\title{
Specialist recertification:
}

\section{a survey of Members and Fellows}

\author{
Kirstyn Shaw, Mary Armitage and lan Starke
}

\begin{abstract}
The Royal College of Physicians has completed a survey of Members and Fellows to ascertain opinions about the development of specialist standards and the applicability of potential methods/evidence for specialist recertification. Of 985 respondents, $68.6 \%$ felt that 11 of the suggested methods would be appropriate for specialist practice and most of these would also be applicable to sub-specialist practice. More than two thirds agreed that it was appropriate to include evidence related to the performance of the clinical team for individual recertification. Respondents expressed concern about the current appraisal process but many felt that it could be effective if it was strengthened and consistently applied.
\end{abstract}

KEY WORDS: appraisal, evidence, performance assessment, recertification, regulation, revalidation

In a follow-up to the publication of the appraisal and revalidation guidance booklets launched in June 2007, ${ }^{1}$ the Royal College of Physicians (RCP) identified the next step in the revalidation programme as a survey of Members and Fellows about specialist recertification. Its purpose was to ascertain views about the development of specialist standards and the applicability of potential methods for specialist recertification.

Within the Department of Health (DH) 2007 White Paper, Trust, assurance and safety, revalidation was divided into the twin processes of relicensure and specialist recertification. ${ }^{2}$ Relicensure will be required for all trained doctors, and the processes to achieve this will be led by the General Medical Council (GMC). Specialist recertification will be required for doctors who are on the specialist register, including general practitioners, and a new role for the medical royal colleges has therefore been identified. The process will be the responsibility of the medical royal colleges who will need to provide a 'positive statement of assurance' that a doctor is up to date and fit to practice. Evidence to support specialist recertification may come from a variety of sources including multisource feedback, patient questionnaires, workplace based assessments such as direct observation of clinical or technical skills, observation of multidisciplinary team working, peer review, clinical audit and evidence of participation in continuing professional development.

If specialist recertification for physicians is to be effective, it is essential that the royal colleges collaborate with the specialties to develop a form of evaluation that is appropriate, relevant and expeditious. For three years, the RCP has been working with the specialist societies to identify potential methods that could be used for recertification. An analysis of the discussion within a series of seven pilot workshops (diabetes, dermatology, gastroenterology, genitourinary medicine, rehabilitation medicine, rheumatology, and stroke medicine) highlighted a list of potential methods in line with the RCP's preferred portfolio approach to the acquisition of evidence for revalidation. In order to plan and prioritise future developments these methods and a range of additional options were included in an electronic questionnaire.

\section{Respondents}

The e-questionnaire was sent to all RCP Fellows and Members and 985 responses were received. All 29 specialties were represented. Nearly half of the respondents worked in acute medicine, geriatric medicine, cardiology, respiratory medicine or gastroenterology. Most worked in an acute trust $(52.4 \%)$ or a district general hospital $(36.3 \%)$ with the remainder working in a primary care trust $(6.7 \%)$, hospice $(2.8 \%)$, the armed services $(0.6 \%)$, prison service $(0.2 \%)$ or as locums $(1 \%)$. In addition to NHS clinical practice, $88.6 \%$ of the respondents were also involved in other forms of work including academia $(24.6 \%)$, private practice $(20.6 \%)$, trust or other professional healthcare, eg royal colleges, British Medical Association or GMC, management and professional representation (40\%).

The majority of respondents $(92.5 \%)$ were listed on the specialist register with enrollment achieved through either Joint Royal Colleges of Physicians Training Board accreditation (56.2\%) or a Certificate of Completion of Training (40.1\%). Of the $7.5 \%$ not listed on the register, $62 \%$ are currently in the process of enrolling, $23 \%$ do not intend to register and $15 \%$ have been deterred from registering as they have
Kirstyn Shaw PhD, Clinical Standards Project Manager, Royal College of Physicians

Mary Armitage FRCP, Immediate Past Clinical Vice President, Royal College of Physicians; Clinical Lead, Modernising Medical Careers, Department of Health

lan Starke FRCP, Medical Director of Revalidation, Royal College of

Physicians 


$\begin{array}{lc}\text { Method } & \begin{array}{c}\text { Percentage appropriate for } \\ \text { generic physician and } \\ \text { specialist practice (\%) }\end{array} \\ \text { Continuing professional development } & 96.7 \\ \text { Peer review } & 83.9 \\ \text { Clinical audit } & 81.0 \\ \text { Multisource feedback (physician) } & 76.2 \\ \text { Multisource feedback (specialty) } & 75.5 \\ \text { Specialty clinical indicators } & 75.3 \\ \text { Personal development plan } & 73.8 \\ \text { Incidents } & 73.5 \\ \text { Implementation of clinical guidelines } & 73.0 \\ \text { Formalised peer networks } & 71.2 \\ \text { Complaints } & 68.6 \\ & \\ & \end{array}$

found the application process for the Certificate of Eligibility for Specialist Registration (CESR) unmanageable.

\section{Results}

Specialist recertification is about specialist practice. It is a process where individual physicians will need to provide evidence to demonstrate that they are practicing their chosen specialty to a given standard. Respondents were asked to indicate to what level of specialist practice standards should be established and the evidence required for specialist recertification - generic physician, specialist practice or subspecialist practice. Standards and evidence across the generic physician and specialist practice level achieved $77 \%$ support with $40 \%$ agreeing that subspecialist practice should also be covered.

More than $68.6 \%$ of respondents believed that up to 11 of the methods listed would be appropriate for demonstrating specialist practice (Table 1). This list remained fairly constant when respondents were asked to indicate appropriateness for their subspecialist practice with only the generic multisource feedback failing to gain at least $63 \%$ approval. It could be argued that some of these methods are more related to the performance of the whole clinical team rather than the individual physician, but $70.5 \%$ of respondents agreed that it was appropriate to include team-based evidence for individual recertification.

Methods with less than one-third approval included procedure simulators (29.7\%), health episode statistics data $(27.4 \%)$, quality of life measures (26.5\%) and formal knowledge assessment $(16.5 \%)$. The lack of support for formal knowledge assessment is not surprising as much of the feedback showed that it is seen as a demonstration of knowledge and not of competence or quality of clinical practice.

In Trust, assurance and safety, appraisal was identified as the key mechanism through which evidence for revalidation is to be demonstrated and evaluated. Respondents were asked if they felt that the current appraisal process was robust enough to support revalidation. Nearly two thirds $(62.6 \%)$ thought that appraisal was currently inadequate, but $70.8 \%$ felt that if appraisal was strengthened and consistently applied throughout the NHS, it could be an appropriate mechanism for revalidation. The inclusion of a more summative, performance element into appraisal was also supported by $61.2 \%$ of the respondents.

\section{Conclusion}

The results of this survey were reassuring in that a majority of physicians supported some form of formal process to gather evidence, and understood that appraisal needs to be strengthened. A series of projects in support of revalidation is currently being initiated. These projects include defining standards for the recertification of physicians, developing and piloting specialty specific questions for multisource feedback, incorporating new reflective elements into continuing professional development, and evaluating new proposals on appraisal to identify ways in which this could be strengthened and improved. The RCP will support Members and Fellows by means of a proactive revalidation work programme and ongoing collaboration with key stakeholders including the specialist societies, DH, Academy of Medical Royal Colleges and the GMC.

\section{References}

1 Royal College of Physicians. Appraisal and revalidation: guidance for doctors preparing for relicensing and specialist recertification. London: RCP, 2007.

2 Department of Health. Trust, assurance and safety - the regulation of health professionals in the 21st century. London: Stationery Office, 2007. 